\title{
Bluetooth Based Smart Home Automation System using Arduino Uno Microcontroller
}

\author{
${ }^{1}$ Mohammed D. Albakhait, ${ }^{2}$ Mohammed S. Hasan and ${ }^{1}$ Alaa A. Hajer \\ ${ }^{1}$ Department of Power Technical Engineering, Electrical Engineering Technical College, \\ Middle Technical University, Baghdad, Iraq \\ ${ }^{2}$ Department of Power and Electrical Machine, University of Diyala, Baqubah, Iraq
}

\begin{abstract}
This study is concerned with using Bluetooth in developing a smart home automation system. As such, life will definitely be much easier for the elderly and the handicapped to control their own life at home by using this study. Moreover, this study is intended to come up with the calculation of the cost of the effective remote controlled home automation system and to identify the needs of the elderly and the handicapped that can be achieved using this project. The ultimate aim of this project is to make the lives of people smooth and more developed. The main device used in this system is the Bluetooth which allows a wireless access to a smartphone. Furthermore, this piece of research keeps a control over the electrical switches with low voltage usage. At the same time, it does not remove the switches. Overall, this research aims at designing a system that can control an electrical device with less cost and more efficiency.
\end{abstract}

Key words: Automation, smart home, home appliances, Bluetooth, Android, switches

\section{INTRODUCTION}

The system of home automation is getting attention and has become known and used all over the world. This system is introduced to control the home appliances. As such, it can be said to be of great value to all people not only the handicapped or the elderly. According to, the way of connection, Home Automation Systems (or HASs) can be classified into wired or wireless connection. As for the wireless connection it is used to get rid of the wired connection to the home appliances. The Arduino and Bluetooth-based home automation will be applied in this study (Javale et al., 2013).

Humans have done a great deal of research in relation to using smart phones. One of such studies highly depended on 5000 people from different countries, namely, USA, United Kingdom, South Korea, India, China, South Africa, Indonesia and Brazil. The results of this study proved that $48 \%$ of them stated that they could not do without their smart phones. In another study, the Android was introduced as having $75 \%$ of the market share. As such, more than 106000000 Android smartphones were shipped to the market in the 2nd half of 2012. Studies also proved that the Android operating system is of the most important and the most popular system for the smartphones (Mahala et al., 2017).
Home automation systems were introduced to improve the life style of people. Besides, they represent the best way to manage the appliances at home. They can be found in Onloff TV turns, automatic open and close of the doors and more and more in power saving (Javale et al., 2013). It can be defined as an open source agenda mainly used to design. It comprises two parts, hardware and software. The former is referred to as a microcontroller (Physical programmable circuit board) and the latter be used to program the microcontroller. Besides, the software is called Integrated Development Environment (IDE).

Arduino as a program is used to run different operating systems such as Windows, Linux, Macintosh and XP, contrariwise other programs that can run only on windows. The board of the Arduino is known to have sets of analog inputloutput. Such sets can be interfaced to many expanded boards and other circuits. Most Arduino boards comprise an Atmel 8 bit AVR microcontroller in addition to various memory sizes, pins and characteristics. (Anwaarullah and Altaf, 2013). When the Arduino board is compared to other microcontrollers it is cheaper no need for a programmer to load a program and a USB cable can be used for that purpose. Moreover, the Arduino software IDE uses a simplified version of $\mathrm{C}++$ and this makes it easier to learn (Anonymous, 2018).

Correspoding Author: Mohammed D. Albakhait, Power Technical Engineering, Electrical Engineering Technical College, Middle Technical University, Baghdad, iraq 
Bluetooth is a technology: Bluetooth is a technology used to transfer data wirelessly between electronic devices. In such a situation, the distance of data transmission is small when compared to other technologies used to transfer data. The benefit of this technology is to annihilate the cords, cables and adapters used and to allow the wireless communication between the electronic devices. Among the advantages of using the Bluetooth technology is that it gives a guarantee for high security in transferring data and it secures it from the external interference in addition to other aspects including strength, energy consumption, low complexity, ease of use and low cost. The difference between Bluetooth and the radio wave technology is that it is used for short distances only $(<10 \mathrm{~m}$ or $30 \mathrm{ft}$ ). The Bluetooth is used to send and receive radio wave data in seventy-nine different frequencies centered on $2.45 \mathrm{GHz}$. What is special about Bluetooth devices is that they detect each other and are connected in an automatic way. In this sense, it is possible for eight different devices to be connected at one time.

In its build-up, each gadget is supposed to have a microchip being installed to receive and transmit the frequency of $2.4 \mathrm{GHz}$. This can be accessible throughout the whole world taking into account some varieties of transmission Bandwidth in different nations. The data developed can be raised up to $1 \mathrm{Mbps}$ ( $2 \mathrm{MB}$ for a second in the second generation of this technology). A plan of "frequency hop" (hops of frequencies) is intended to let the gadgets be connected comprehensively. This case can be done even in territories where there exists a strong electromagnetic interference in addition to having plans of encryption and check. When a set of Bluetooth gadgets introduced as a system it is called "picante" as shown in Fig. 1.

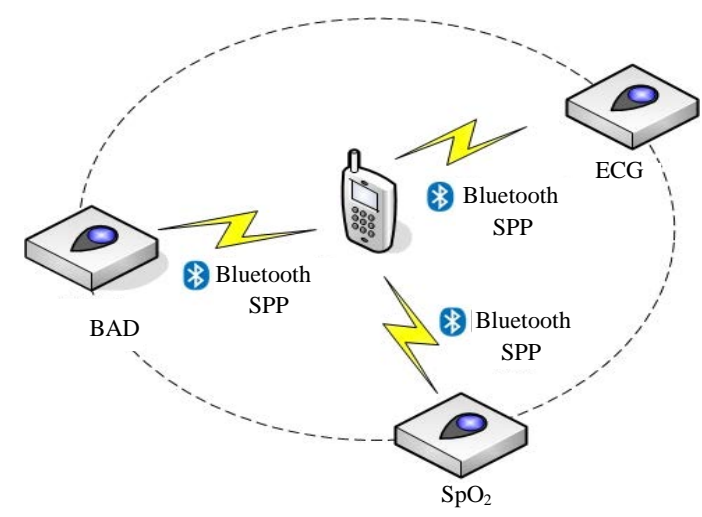

Fig. 1: System of set of Bluetooth gadgets
Because the Arduino cannot perform a direct connection to the device an $\mathrm{HC}-06$ Bluetooth module is used to connect the Arduino microcontroller to the Android Smartphone. In this regard, it is stated that the $\mathrm{HC}-06$ module is easy to setup and it can be programmed using AT command. Furthermore, the module has two fixed modes only, namely, master and slave in this research, a slave mode is used.

\section{MATERIALS AND METHODS}

Android operation system: Android operation system is a kind of systems developed for mobile phones already developed by Google. Besides, it can be regarded as one the best-selling operating systems in the world. Moreover, large amounts of comfortable and advanced applications are supported by the android (Liu and $\mathrm{Yu}$, 2011).

The Android application store is called Google play store. As such, it has more than 3.5 million applications run by Android. Android building design consists few layers as demonstrated in Fig. 2. To get to the hardware, the applications required need to go layer by layer. The principal equipment platform used for Android is the ARM architecture (Anonymous, 2014).

There are two types of communication used in this research, namely, wireless and wired communication. The former is the wireless as shown in Fig. 3 and 4. It has been done using the $\mathrm{HC}-05$ Bluetooth module the latter is the wired communication. Moreover, the appliances are connected directly to the controller. Figure 5 shows the basic parts of the system, namely, Arduino microcontroller, An HC-05 Bluetooth module, relays, Android device and android software that control the system.

Arduino Uno is an ATmega328p microcontroller board. There are about 20 digital inputloutput pins in it. Another point to add is that whatever needed to support the microcontroller is there on the Arduino. Besides, it can be connected to a computer by simply using USB cable and it can be powered by the use of AC-DC adapter or battery to get started.

Arduino can be introduced as an open source hardware where it can sense the environment through a number of sensors connected to it. It is a project that can stand-alone or connected to a software running on a computer (Anonymous, 2018) Fig. 6.

As stated before, the Bluetooth module used in the present work is an $\mathrm{HC}-06$ module. It is a two-slave module primarily used for wireless serial communication. Furthermore, it can be connected to a PC, smartphone or 


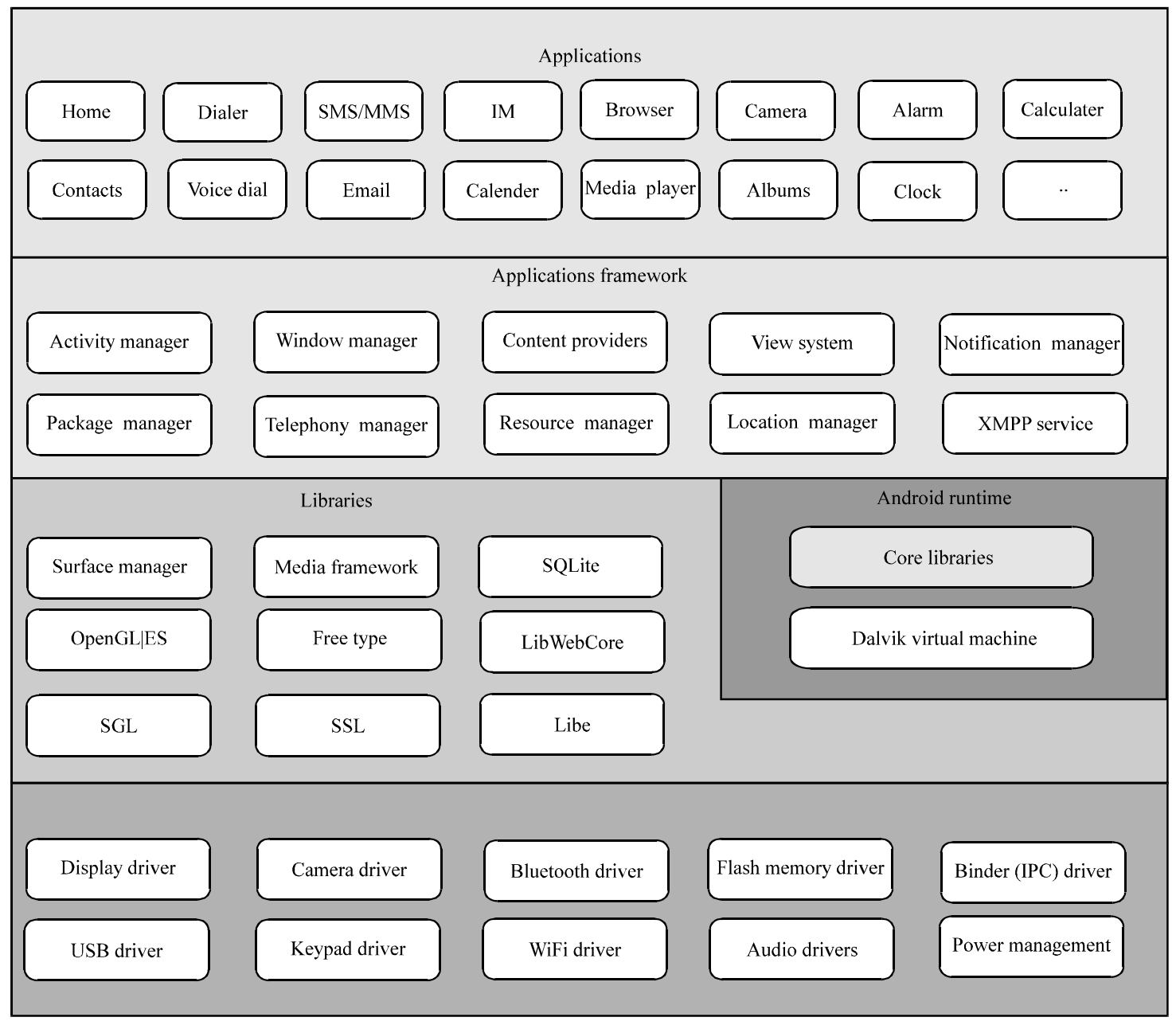

Fig. 2: Android system architecture

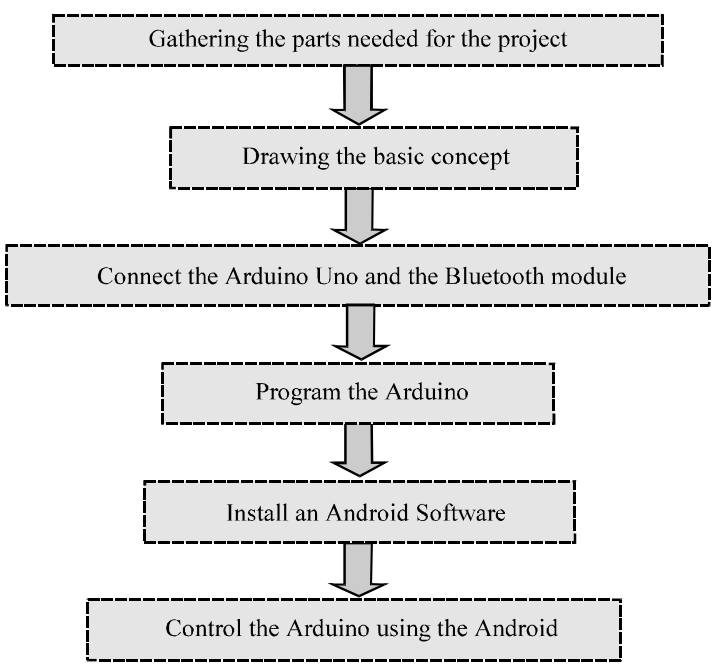

Fig. 3: The flow-chart of the work from the beginning to the end

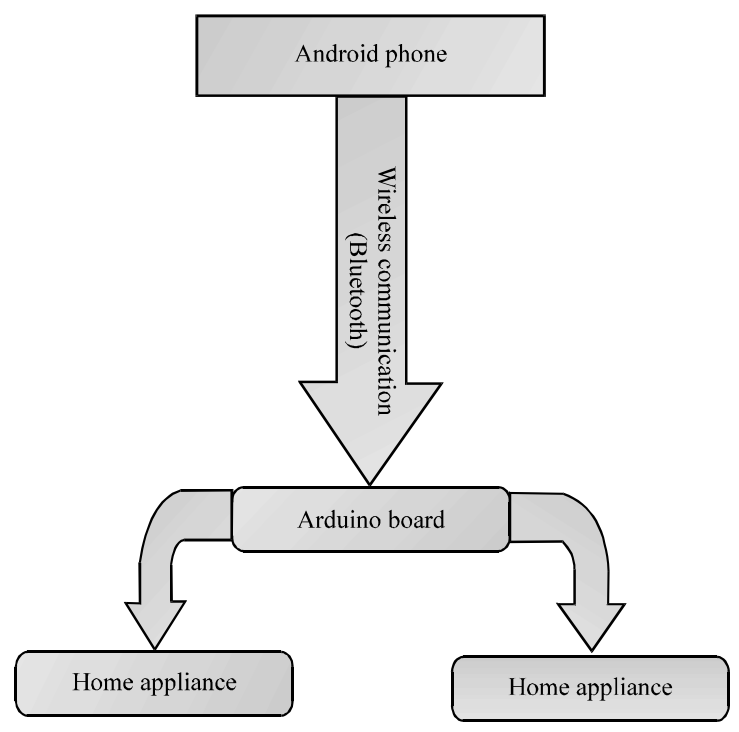

Fig. 4: Project flow chart 


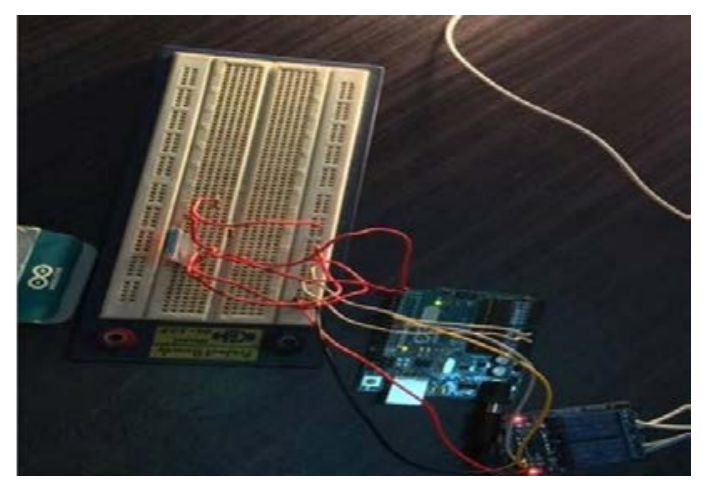

Fig. 5: Hardware implementation

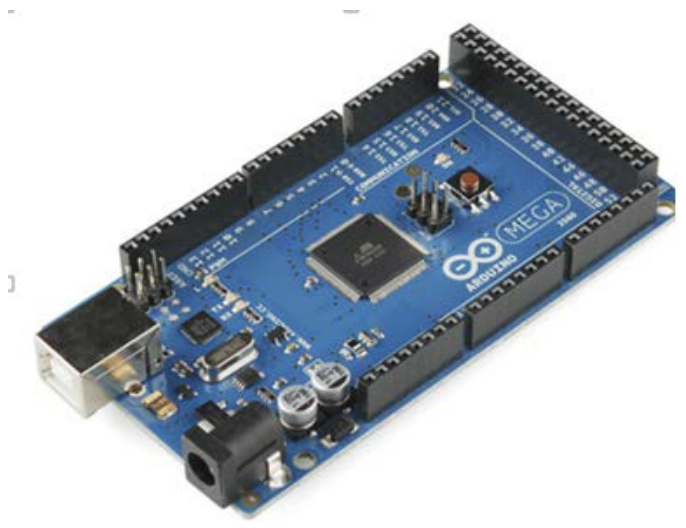

Fig. 6: Arduino Uno structure

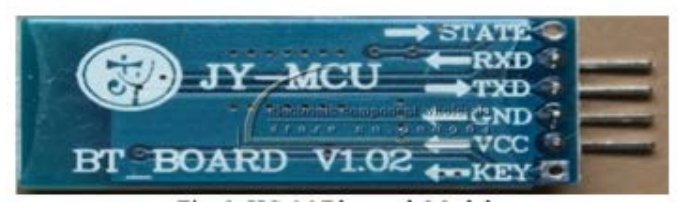

Fig. 7: HC-06 Bluetooth module

a tablet master Bluetooth devices. This module can be Fig. 7. The HC-06 is designed to operate with 3.6-6 VDC. In this process, the data is transmitted wirelessly through the air.

The other point to emphasize is that the system consists of a number of relays as shown in Fig. 8. A relay can be defined as a switch that operates electrically. It is used when there are several circuits and there is a need to be controlled by one signal. Besides, a small electrical current can operate the relay on or off. Of the operation in the relay relies on two modes: active high and active low. In case the active high is preferred, the power source is connected to the in port and the appliance is connected to the Normally Open (NO) port, if not, the appliance is connected to the Normally Close (NC) pin.

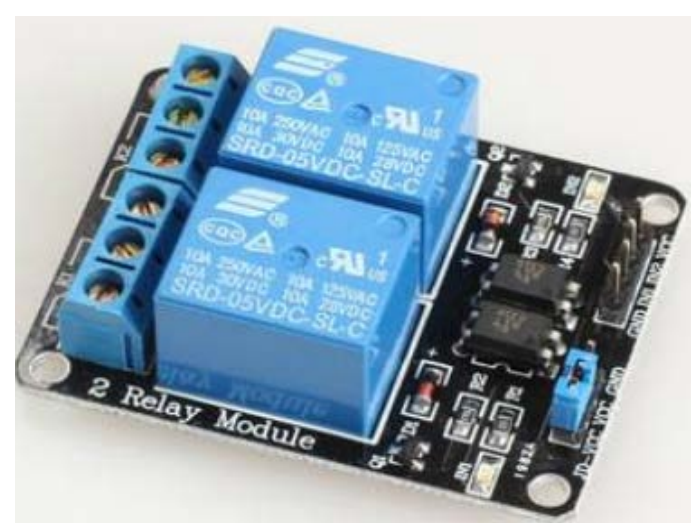

Fig. 8: Two relay module

ArduDroid is an Android application that can be installed on the smartphone (Galaxy S phone used in this study). What is of value here is that the Galaxy S Android Smartphone can be used as a remote control for the System. As such, the App can possibly make the wireless control of the Arduino pins. For the purpose of the present study, only the digital pins are required in, so doing, the programming of the Arduino will only focus on these pins.

Programming the Arduino Uno: The Arduino company usually provides an open source software called Arduino IDE. This software allows any programmer to write the codes for the desired function required to be performed by the Arduino microcontroller.

Connecting the Arduino Uno board to the Bluetooth: A connection between the Bluetooth module and the Arduino is highly required for the Android smartphone in order to control the $\mathrm{m}$ icrocontroller. This connection is shown in Fig. 9 where the VCC port of the Bluetooth module must be connected to the VCC port of the Arduino. In this connection, the ground pin of the module is connected to the ground pin of the Arduino. The receiver of the module, on the other hand, must be connected to the transmitter of the Arduino as well as the transmitter of the module must be connected to the receiver of the arduino. When these two steps are insured, the connection between the Bluetooth module and the Arduino is considered complete.

Testing the connection: To insure a successful connection of the circuit, the following steps must be met: 


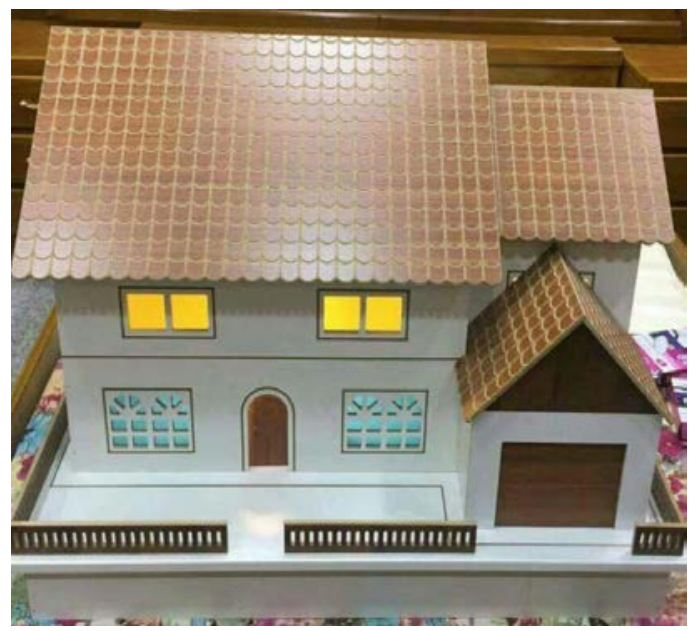

Fig. 9: Experimental setup smart home

- Install the Apps on the phone

- Open the App after the installation is complete

- Search for the available Bluetooth devices using the App

When the Bluetooth module is shown in the Bluetooth available list, connect to it. When the connection is done, the light in the Bluetooth module will stop blinking. This means everything is fine or else the wiring needs to be checked again.

Connecting the appliances to the Arduino board: Connecting the home devices to the system comes as a result to the connection between the Arduino and the smart phone which is done through the Bluetooth module. This means that they need to be connected to the Arduino. In this regard, the connection can be achieved through the relays by using wires and connector blocks. Here, the positive end of the device is to be connected to the Normally Open (NO) Pin of the relay. This is because the connection to the NO means that the device will work on the active high mode. The negative end of the device, on the other hand is connected to the power source. In so doing, the $\mathbb{N}$ port of the relay is expected to connect to any port of the Arduino. An important point to mention, here is that only the digital inputs were used in the present paper.

\section{RESULTS AND DISCUSSION}

Finalized hardware is shown in Fig. 10. The android operated smart home was designed and implemented. The results of the present research study are promising and of great value because the uses can be achieved by anyone

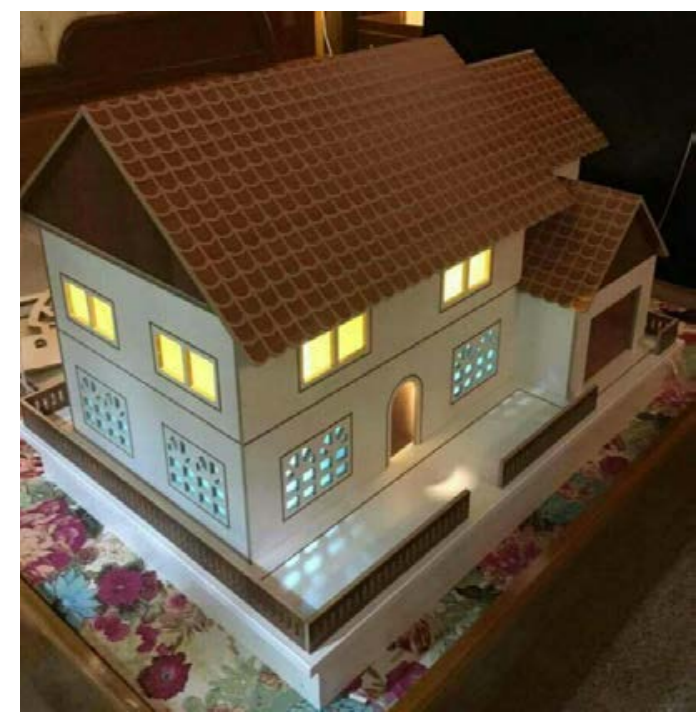

Fig. 10: Experimental setup smart home

by just clicking on the suitable button on the Android smartphone's screen. From an economic view point, the system was cost-effective and the cost was determined only by the prices of the controller's circuit. Another point to consider here is that there were some obstacles at the beginning, one of them is the connection between the Android phone and the microcontroller, since, the Bee module was first used instead of the Bluetooth module. This obstacle was overcome when an HC-06 Bluetooth module was used. The other obstacle was concerned with the relays and the way to connect them to the devices and to the breadboard as well. Finally, this obstacle was also overcome by hard work of calibration.

\section{CONCLUSION}

Home automation system using Arduino and Bluetooth was a real success simply because the system was user friendly and the cost was largely reasonable. The aims of this study were successfully achieved and they are as follows:

- An automation system controlled by a smart phone was constructed for homes

- Designing a system to help the elderly and handicapped met the aim requirements

- The system was cost-effective

\section{REFERENCES}

Anonymous, 2014. The world's most popular mobile OS. Astrium Company, Paris, France. https:// www.android.com/ 
Anonymous, 2018. What is Arduino? Arduino, https://www.arduino.cc/.

Anwaarullah, S. and S.V. Altaf, 2013. RTOS based home automation system using android. Intl. J. Adv. Trends Comput. Sci. Eng., 2: 480-484.

Javale, D., M. Mohsin, S. Nandanwar and M. Shingate, 2013. Home automation and security system using Android ADK. Intl. J. Electron. Commun. Comput. Technol., 3: 382-385.
Liu, J. and J. Yu, 2011. Research on development of android applications. Proceedings of the 2011 4th International Conference on Intelligent Networks and Intelligent Systems (ICINIS), November 1-3, 2011, IEEE, Kunming, China, ISBN:978-1-4577-1626-3, pp: 69-72.

Mahala, V., R. Mangal, R. Kumar and R. Namdev, 2017. Home automation using android phone. Imperial J. Interdiscip. Res., 3: 313-315. 